Journal of Economics and Behavioral Studies (ISSN: 2220-6140)

Vol. 7, No. 6, pp. 72-80, December 2015

\title{
Do parents Influence the Choice of Tertiary Institutions for their Children? Some Statistical Analyses
}

\author{
Kwabena A. Kyei, A. Muthelo \\ University of Venda, Thohoyandou, Limpopo province, South Africa \\ Kyei61@gmail.com
}

\begin{abstract}
The paper investigates whether or not parents influence their children's choice for tertiary institution to attend. Education has increasingly become more important in this present age to the extent that, without higher qualifications, employment and success become very difficult to achieve. Parents are trying to send their children to tertiary institutions so that these children will be employable. But the question is: Do parents choose the tertiary institutions for their children? The paper wants to find out whether or not parents have a say in their children's choice for tertiary institution; and if so, look at factors that could play in the choice. A survey was conducted at the University of Venda from February 2015 to June 2015 and 500 students were conveniently sampled and interviewed. Using some statistical analyses, including Generalized Linear Modelling (GLM), the study concludes that age and the campus environment are the only factors that determine parents' influence on their children's choice for higher education. The study further shows that female students are more influenced by their parents than males in the choice of higher institution.
\end{abstract}

Keywords: Choice, tertiary institutions, multiple logistic regressions

\section{Introduction}

The post-apartheid era in South Africa, (i.e. after democracy in 1994), has been characterised by major restructuring of the higher education landscape in the country. Higher education institutions are faced with, among other things, globalisation, broadened access to higher education, changes in language policies, changes in government funding, increased emphasis on technology, transformation policies, mergers, HIV/AIDS, changing student profiles and increased competition (Fataar, 2003; Jansen, 2003; Van Niekerk, 2004; Akoojee \& Nkomo, 2007). There has been a growing need for higher education in order to find employment; and this makes it crucial for the choice of institution to go for further studies. Tertiary education is vital in sustaining a good career for oneself, because, nowadays, future employers place greater importance and preference when employing candidates based on their qualifications; and where they obtained such qualifications. This has placed an even greater pressure on students when selecting an institution to continue further studies. This research has been prompted to investigate if parents influence their children's choice for tertiary institutions, using students from the University of Venda as a case study. The study wants to see which of the independent variables, age, distance from home to the institution, gender, family background, reputation of the institution, etc., would be the most influential factors when parents choose or not where their children go to do their tertiary education.

\section{Literature Review}

There are quite a number of studies that have been carried out to identify factors that affect student's decision in choosing a Higher Education destination. Basically the factors can be classified into two, i.e. the 'pull factor' and the 'push factor'. The pull factors relate to the issues associated with the benefits or advantages offered by the institutions; for example fees charged, reputation of the institutions, social, culture and values, facilities, etc. On the other hand, the push factors are those associated directly with the home situation such as the level of wealth of the family, the priority of education for the family, the health of the family economy and the educational opportunities available at home. Both factors, i.e. the pull and the push are in fact important factors in determining the local mobility of students in searching for better education. But nevertheless, it is interesting to note that the pull factors are the factors which the Higher Education institutions have control. Thus, it is crucial to identify what are the pull-push factors which really affect the students' decision in choosing their higher education destination. Sevier (1994) stated that research has 
consistently shown that location of a university is an important factor for potential students when considering where to apply to/enrol. Some students may be looking for a place closer to their hometown if not in their hometown itself, since it is cheaper, more convenient and more easily accessible (Sevier, 1994; Absher and Crawford, 1996). Some parents prefer their children to go to a Higher Education Institution which is closer to home so that the children stay at home, and the parents get chance to monitor them; that also reduces costs. When they are far away from home, some students are playful and they end up failing, wasting money and time for a whole year. The failure eventually adversely affects the parents financially.

Institutional image and reputation has a tremendous effect on university's choice. It is a powerful influence on potential students and university reputation is extremely persuasive when looking for an institution to develop ones' education. Keling et al. (2007) stated that the most influential factor that students evaluate in selecting their choice of institution was reputation of the institution. Joseph and Joseph (2000) have advanced that cost-related issues seem to have more importance in determining where a child should go to study. The opinions of family members may exert different types of influence on one's behaviour (Bearden and Etzel, 1982). Family recommendations and opinions influence students' options of their host institutions (Morgan, Baron and Harris, 1999; Bourke, 2000). This is largely because parents have to fund the education hence both the cost and psychological separation play an important role. Absher and Crawford (1996) stated that educational facilities such as classrooms, laboratories and libraries are important in a student's selection of a college or university. It has been observed lately that, since the world is becoming more and more technological dependent, it is imperative to get into an institution where all the necessary and quality technological facilities are available.

\section{Methodology}

Material/Data: Data were collected from the students of University of Venda between February 2015 and June 2015. About 500 students were conveniently sampled and interviewed. A convenience sampling method was used because sampling frame was not easily available. Besides, not all of the students were willing to take part in the survey; this method enabled accessible and "kind-hearted" students to join in the exercise voluntarily. There is no need for call-back and/or re-visitation for convenience sampling. A five level Likert scale was used with some of the questions in the questionnaire being; strongly disagree (SD), Disagree (D), Uncertain (U), Agree (A) and strongly agree (SA) as options in the scale. Face to face interviews were used for sampled participants (Denzin \& Lincoln, 2000). A pilot survey was first conducted to allow the researchers to obtain basic data and trends regarding the study.

Methods/Analysis: Generalized Linear Models (GLM), Multiple Logistic regression and Discriminant function analysis (DA) were used. Generalized linear models are a broad class of statistical models that relate the mean of the response variable to a combination of linear predictors. These Models can handle more complicated situation such as analysing simultaneously the effects of several explanatory variables. The structure of the model describes patterns of association and interaction. The size of the parameters determines the strength and importance of effects. GLM's encompass ordinary regression and ANOVA models for continuous responses and also models for discrete responses. GLM predicts an outcome variable that is categorical from predictor variables that are continuous or categorical (Hair Jr et al. 1995; Agresti, 1996). These models comprise three components: random component identifies the response variable and selects a probability distribution for it; the systematic component specifies the explanatory variables as a linear combination; and the link function connects the expected value of random component and systematic component. The random component can assume any distribution in the exponential family of distributions. Distributions belong to the exponential family of distributions if their probability mass (or density) functions can be expressed in the form:

where,

$$
\mathrm{f}(\mathrm{y} ; \theta, \varphi)=\exp \left\{\frac{y_{i} \theta_{i}-b\left(\theta_{i}\right)}{a_{i}(\phi)}+c\left(y_{i}, \phi\right)\right\}
$$

$\mathrm{y}=$ random component

$\mathrm{a}, \mathrm{b}$ and $\mathrm{c}=$ arbitrary functions

$\varphi=$ dispersion parameter

$\theta=$ canonical parameter 
Logistic regression refers to methods for describing the relationship between a categorical response variable and a set of predictor variables. The Logistic regression assumes that the relationship between the predictor and the response variable is nonlinear. Its model assumption is different from that of linear regression. Since the response of logistic regression is dichotomous, the errors can take only one of two possible forms: $(Y=0$ or $Y=1)$, with their probabilities [1- $\pi(\mathrm{x})$ and $\pi(\mathrm{x})]$ for absence and presence respectively. The variance of the error term, $\varepsilon$, is $\pi(\mathrm{x})[1-\pi(\mathrm{x})]$ which is the variance for a binomial distribution. The response variable in logistic regression, $Y=\pi(\mathrm{x})+\varepsilon$, is assumed to follow a binomial distribution with probability of success, (Larose, 2006: 155 - 166).

Multiple Logistic regression is logistic regression in which more than one predictor variable is used to classify the binary response, (Larose, 2006: 178 - 183). DA undertakes the same task as multiple linear regressions by predicting an outcome (Fielding \& Gilbert, 2006). It is used to determine which continuous variables discriminate between two or more naturally occurring groups. The independent variables are the predictors and the dependent variables are groups. However, multiple linear regression is limited to cases where dependent variables on the $y$-axis is an interval variable so that the combination of predictors will, through the regression equation, produce estimated mean population numerical $y$ values for given values of weighted combinations of $x$ values (Hair Jr. et al., 1995, Agresti, 1996). The discriminant analysis involves the determination of a linear equation like regression that will predict which group the case belongs to. The function is:

Where, $\mathrm{D}=$ discriminant function

$$
\mathrm{D}=V_{1} X_{1}+V_{2} X_{2}+V_{3} X_{3}=\ldots \ldots \ldots \ldots V_{i} X_{i}+\mathrm{a}
$$

$$
\begin{aligned}
& \mathrm{V}=\text { the discriminant coefficient/ weight for that variable } \\
& \mathrm{X}=\text { respondent's' score for that variable } \\
& \mathrm{a}=\mathrm{a} \text { constant } \\
& i=\text { the number of predictor variables }
\end{aligned}
$$

\begin{tabular}{|c|c|c|c|c|}
\hline & & & $\mathbf{N}$ & Percent \\
\hline \multirow[t]{3}{*}{$\overline{\text { Dependent Variable }}$} & \multirow{3}{*}{$\begin{array}{l}\text { Did your parents influence your decision on } \\
\text { which tertiary institute to attend? }\end{array}$} & Yes & 255 & $51.1 \%$ \\
\hline & & No & 244 & $48.9 \%$ \\
\hline & & Total & 499 & $100.0 \%$ \\
\hline \multirow[t]{19}{*}{ Factor } & \multirow[t]{3}{*}{ Gender } & male & 288 & $57.7 \%$ \\
\hline & & female & 211 & $42.3 \%$ \\
\hline & & Total & 499 & $100.0 \%$ \\
\hline & \multirow{3}{*}{$\begin{array}{l}\text { If Univen was situated in a more urban area } \\
\text { would you have given it a first choice } \\
\text { preference? }\end{array}$} & Yes & 364 & $72.9 \%$ \\
\hline & & No & 135 & $27.1 \%$ \\
\hline & & Total & 499 & $100.0 \%$ \\
\hline & \multirow{3}{*}{$\begin{array}{l}\text { Would you refer other people to come and } \\
\text { further their education at Univen? }\end{array}$} & Yes & 377 & $75.6 \%$ \\
\hline & & No & 122 & $24.4 \%$ \\
\hline & & Total & 499 & $100.0 \%$ \\
\hline & \multirow[t]{6}{*}{ University students prefer to stay on campus } & SD & 221 & $44.3 \%$ \\
\hline & & $\mathrm{D}$ & 79 & $15.8 \%$ \\
\hline & & $\mathrm{U}$ & 9 & $1.8 \%$ \\
\hline & & $\mathrm{A}$ & 41 & $8.2 \%$ \\
\hline & & SA & 149 & $29.9 \%$ \\
\hline & & Total & 499 & $100.0 \%$ \\
\hline & \multirow{4}{*}{$\begin{array}{l}\text { University environment / residence, makes it } \\
\text { hard to study (section 2.4) }\end{array}$} & SD & 44 & $8.8 \%$ \\
\hline & & D & 27 & $5.4 \%$ \\
\hline & & U & 103 & $20.6 \%$ \\
\hline & & A & 95 & $19.0 \%$ \\
\hline
\end{tabular}

The discriminant analysis creates an equation which will minimize the possibility of misclassifying cases into their respective groups or categories. Cases are classified as predicted (Hair Jr. et al., 1995).

\section{Results}

Table 1: Categorical Variable Information 


\begin{tabular}{lcll} 
& SA & 230 & $46.1 \%$ \\
Was Univen your first choice? & Total & 499 & $100.0 \%$ \\
& Yes & 280 & $56.1 \%$ \\
you can afford to go study elsewhere & No & 219 & $43.9 \%$ \\
& Total & 499 & $100.0 \%$ \\
& SD & 204 & $40.9 \%$ \\
D & 99 & $19.8 \%$ \\
U & 72 & $14.4 \%$ \\
A & 51 & $10.2 \%$ \\
SA & 73 & $14.6 \%$ \\
Total & 499 & $100.0 \%$ \\
\hline
\end{tabular}

The exploratory data analysis reveals that the youngest respondent was 17 years old and the oldest was 37 years. The mean age of the respondents (students) was 21.20 years. From the 500 respondents, the majority of 282 students were Venda speaking, (i.e. 56.4\%); and were followed by Tsonga speaking people who accounted for $15.8 \%$. These figures did not come as a surprise to the researchers because the University of Venda is situated in Venda so it is bound to have a higher percentage of Venda speaking students.

Table 2: Crosstab

\begin{tabular}{|c|c|c|c|c|}
\hline & & $\begin{array}{l}\text { Gender } \\
\text { male }\end{array}$ & Female & Total \\
\hline \multirow{4}{*}{$\begin{array}{l}\text { Did your parents influenceyes } \\
\text { your decision on which } \\
\text { tertiary institute to attend? }\end{array}$} & Count & 141 & 114 & 255 \\
\hline & $\%$ within Did your parents & & & \\
\hline & $\begin{array}{l}\text { influence your decision on which } \\
\text { tertiary institute to attend? }\end{array}$ & $55.3 \%$ & $44.7 \%$ & $100.0 \%$ \\
\hline & $\%$ within gender & $49.0 \%$ & $54.0 \%$ & $51.1 \%$ \\
\hline \multirow[t]{3}{*}{ no } & Count & 147 & 97 & 244 \\
\hline & $\begin{array}{l}\% \text { within Did your parents } \\
\text { influence your decision on which } \\
\text { tertiary institute to attend? }\end{array}$ & $60.2 \%$ & $39.8 \%$ & $100.0 \%$ \\
\hline & $\%$ within gender & $51.0 \%$ & $46.0 \%$ & $48.9 \%$ \\
\hline \multirow[t]{3}{*}{ Total } & Count & 288 & 211 & 499 \\
\hline & $\begin{array}{l}\% \text { within Did your parents } \\
\text { influence your decision on which } \\
\text { tertiary institute to attend? }\end{array}$ & $57.7 \%$ & $42.3 \%$ & $100.0 \%$ \\
\hline & $\%$ within gender & $100.0 \%$ & $100.0 \%$ & $100.0 \%$ \\
\hline
\end{tabular}

From Table 1 we see that the majority of the respondents were males, 288 (57.7\%) and 211 (42.3\%) females. About $51.1 \%$ of the respondents said yes (to the question whether) their parents influenced their decision on which tertiary institution to attend. In Table 2, it can be seen that $49 \%$ of the male respondents and $54 \%$ of the females were influenced by their parents. This came as no surprise to the researchers because parents tend to influence their daughters more easily since they are less rebellious, more considerate and are willing to compromise. In the same Table $1.1,56.0 \%$ responded positively (i.e. yes) to whether they considered Univen as their first choice. This information was insightful in helping to get a clearer view of students' or people's views with regard to Univen as an institution. This figure shows that Univen attracts quite a sizeable number of students despite its location. The figure was further confirmed by the fact that $72.9 \%$ said they would give Univen a first choice preference, if it were situated in a more urban area. This bodes well for the University of Venda in the sense that it is still attractive, especially to local people and can attract future prospective students.

\section{Multiple Logistic Regression Model}

Table 3: Goodness of fit (Omnibus Test)

\begin{tabular}{lll}
\hline Likelihood Ratio Chi-Square & Df & Sig. \\
\hline 23.299 & 12 & .025 \\
\hline
\end{tabular}


We observed in the Goodness of Fit table, Table 3 and Table A3 (in appendix) that the overall regression is significant as shown by the $p$-value of 0.025 . That is all the independent variables are collectively significant when we compare the fitted model against the intercept-only model. However we need to test whether all the variables are relevant in the model. Table 4 tells us that age (with $p$-value of 0.012 ) and university environment (with $p$-value of 0.026 ) are the variables that contribute to the model.

Table 4: Tests of Model Effects

\begin{tabular}{llll}
\hline Source & $\begin{array}{l}\text { Type III } \\
\text { Wald Chi-Square }\end{array}$ & Df & Sig. \\
\hline (Intercept) & 5.106 & 1 & .024 \\
Gender & 1.453 & 1 & .228 \\
Q7 & .037 & 1 & .847 \\
Q9 & .012 & 1 & .914 \\
section2.1 & 1.748 & 4 & .782 \\
University Environ & 11.084 & 4 & .026 \\
Age & 6.344 & 1 & .012 \\
\hline
\end{tabular}

Dependent Variable: Did your parents influence your decision on which tertiary institute to attend?

Model: (Intercept), gender, Q7 (Univen first choice), Q9 (refer others), section2.4, $(=$ Campus environment), age

In Table 4, we find out that the factors which determine parents' influence on the choice of their children's Higher Education Institution are age and campus environment (i.e. $Q$ in section 2.4). The mean age is21.20 years, this indicates the fact that our respondents are not quite old, still fairly young (in African context) and can still be manipulated by parents who pay for their education.

\section{GLM Results}

Table 3: Parameter Estimates

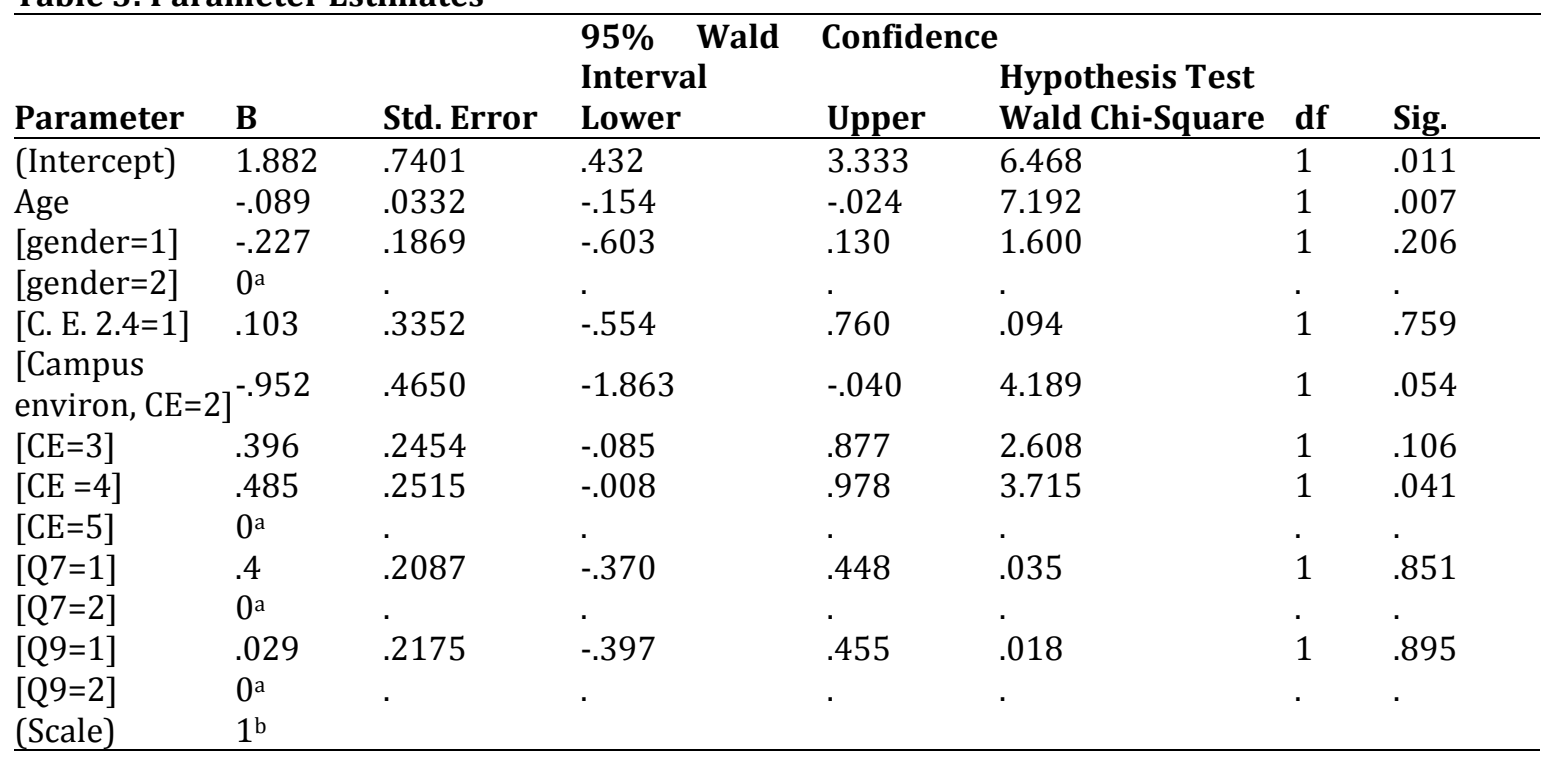

Dependent Variable: Did your parents influence your decision on which tertiary institute to attend?

Model: (Intercept), age, gender, section2.4, Q7, Q9

Set to zero because this parameter is redundant.

b. Fixed at the displayed value.

Table 3 tells us again that age and Campus Environment (CE) are the only variables that are important in the analysis of whether parents influence or not their children on the choice of tertiary institution. The same table (Table 3) further tells us that if female was taken as our base for gender, the male has a negative value (0.227) which interprets to $20 \%$ lower. This supports the earlier statement that parents have a higher 
influence on female children than they have on male children (i.e. $20 \%$ less). When we look at the case whether respondents would give Univen first choice preference (Question 7) if it were situated in a more urban area, we see a high score for yes (0.4) which translates to $49 \%$ higher. This confirms the earlier statement that more people said yes; i.e.72.8\% responded that they would give Univen a first choice.

Discussion: Both the GLM and the Multiple Logistic regression methods from Tables 2.1, 2.2, 3; as well as Tables A1, A2 and A3, in the appendix, tell us that the variables that are useful in the model are age and campus environment. This means that these two variables are useful in classifying influence of parents on their children's choice for tertiary institutions. The negative sign for age means that when children are growing, parents are no longer able to influence them. On the other hand, the positive sign for the campus environment means that if Univen or for that matter, any campus being considered, is in more urbanised area with good infrastructure, more students will be attracted to it so parents can influence their children to choose such campus.

Mathematically, the model equation is given by

$$
\begin{aligned}
& \text { Logit }[\theta(\mathrm{x})]=\log \left[\frac{\theta(x)}{1-\theta(x)}\right]=\alpha+\beta_{1} x_{1}+\beta_{2} x_{2}+\ldots+\beta_{i} x_{i} \\
& \qquad \begin{array}{l}
\text { Logit }[\theta(\mathrm{x})]=\beta_{0}+\beta_{1}(\text { age })+\beta_{2} \text { (campus environment). } \\
\text { Log odd }=1.882-.227 \text { age }+.485 \text { campus environment. }
\end{array} \\
& \text { This implies that } \\
& \text { Odd ratio }=6.57+0.797 \text { age }+1.62 \text { campus environment. }
\end{aligned}
$$

We now look at the discriminant procedure. The results seen in Table 4a, that is, the Box's M tests results, show that the covariance matrices do not differ between groups formed by the dependent. The value of 25.33 with $\mathrm{F}=25.294$ is significant at $\mathrm{p}$-value $<0.000$. This means one can proceed with the analysis.

\begin{tabular}{lll}
\multicolumn{3}{l}{ Table 4a: Test Results } \\
\hline Box's M & & 25.344 \\
F & Approx. & 25.294 \\
& df1 & 1 \\
& df2 & 740059.474 \\
& Sig. & .000 \\
\hline
\end{tabular}

Again as seen from Table $4 \mathrm{~b}$, the results from this method also confirm that only one variable which is age can predict parents' influence on their children's choice. The following equation is derived from Table 4b:

$\mathrm{D}=(0.340 \mathrm{x}$ age $)-7.206$ $-4.1$

\section{Table 4b: Canonical Discriminant Function Coefficients}

\begin{tabular}{ll}
\hline & Function \\
& 1 \\
\hline Age & .340 \\
(Constant) & -7.206 \\
\hline
\end{tabular}

The stepwise statistics in Table 4c shows that only one variable (one step) added to the intercept only. Wilks' Lambda in Table $4 \mathrm{~d}$ indicates the significance of the discriminant function. The table further indicates a highly significant function ( $p$-value $<0.005)$ and provides the proportion of total variability not explained.

Table 4c: Variables in the Analysis

\begin{tabular}{llll}
\hline Tep & & Tolerance & F to Remove \\
\hline 1 & Age & 1.000 & 8.032 \\
\hline
\end{tabular}

Table 4d: Wilks' Lambda

\begin{tabular}{lllll}
\hline Test of Function(s) & Wilks' Lambda & Chi-square & Df & Sig. \\
\hline 1 & .984 & 7.960 & 1 & .005 \\
\hline
\end{tabular}


A Lambda of 1.00 occurs when observed group means are equal (all the variance is explained by factors other than difference between those means), while a small Lambda occurs when within-groups variability is small compared to the total variability. Here, the Lambda of 0.984 has significant value (sig $=0.005$ ), thus the group means appear to differ. Table A4 - standardized canonical discriminant function coefficients, (in appendix), gives age (.842) and campus environment (-.439); showing that the coefficients of these two factors are significant. This confirms that age and campus environment are the only important factors from the discriminant analysis. In short all the three methods affirm that the factors that are useful in predicting that parents' influence on the choice of tertiary institutions for their children are age and campus environment. One expected that the reputation of the institution, financial position of the family and even distance from home to the institution, just to cite a few, could be useful predictors, but the results here have proved otherwise (Soutar \& Turner, 2002).

Limitation of the study: The sample size used could have been increased were it not time constraint. There is a probability that some of the respondents were not honest or truthful with their answers. The Convenience sample which is Non-Probability sampling method used is limited and therefore we cannot make an inference from the results.

\section{Conclusion}

The study set out to investigate whether or not parents influence their children's choice for tertiary institution using a case study of the University of Venda. The analysis was based on three statistical methods, Generalized Linear Models, Multiple Logistic Regression and Discriminant analysis. The results from the analyses revealed that only two variable, ages, and campus environment contributed significantly to the question whether parents have any influence on their children's choice for tertiary institution. In step-wise discriminant analysis only one step was taken meaning that there were no other variables added in the analysis; this further supported the results we found in the generalized linear model and the multiple logistic regression analyses. In conclusion, this study has shown that the most predictive factor which has been confirmed by the Discriminant Analysis as well as the GLM is Age. Campus environment is also useful in the model. The other independent variables considered in the research are non-significant and not useful.

Recommendation: The paper recommends that parents should start dialogue with their children from a young age regarding their future; in so doing they are imparting precious knowledge to the children and enabling them to make their own decisions when the time comes for them to make choices.

\section{References}

Absher, K. \& Crawford, G. (1996). Marketing the community college starts with understanding students' perspectives. Community College Review, 23(4), 59-67.

Agresti, A. (1996). An Introduction to Categorical Data Analysis. New York: Wiley \& Sons.

Akoojee, S. \& Nkomo, M. (2007). Access and quality in South African higher education: the twin challenges of transformation. South African Journal of Higher Education, 12(3), 385-399.

Bearden W. O. \& Etzel, M. J. (1982). Reference Group Influence on Product and Brand Purchase Decisions. Journal of Consumer Research, 9, 183-481.

Bourke, A. (2000). A model of the determinants of international trade in higher education. The Service Industries Journal, 20(1), 110-138.

Denzin, N. K. \& Lincoln, Y. S. (2000). Handbook of qualitative research $2^{\text {nd }}$ edition. Thousand Oaks, CA: Sage

Fataar, A. (2003). Higher education policy discourse in South Africa: A struggle for alignment with macro development policy. South African Journal of Higher Education, 17(2), 31- 38.

Fielding, J. \& Gilbert, N. (2006). Understanding Social Statistics $2^{\text {nd }}$ Edition. Sage: London.

Hair, J. F. Jr., Anderson, R. E., Tatham, R. L. \& Black, W. C. (1995). Multivariate Data Analysis with Readings $4^{\text {th }}$ Edition. New Jersey: Prentice Hall.

Jansen, J. D. (2003). On the state of South African universities. South African Journal of Higher Education, $17(3), 9-12$.

Joseph, M. \& Joseph, B. (2000). Indonesian students' perceptions of choice criteria in the selection of tertiary institutions: Strategic implications. International Journal of Educational Management, 14 (1), 40-44. 
Keling, S. B. A., Krishnan, A. \& Nurtjahja, O. (2007). Evaluative criteria for selection of private universities and colleges in Malaysia. Journal of International Management Studies, 2(1), 1-11.

Larose, D. T. (2006). Data Mining Methods and Models. Wiley- Interscience. New Jersey: John Wiley \& Sons, Inc, Hoboken.

Morgan, Y. J., Baron, S. \& Harris, K. (1999). Decision-Making Behaviour of Potential Higher Education Students. Higher Education Quarterly, 53(3), 211-228.

Servier, R. A. (1986). Freshmen at competitive liberal arts college: A survey of factors influencing institutional choice. Unpublished dissertation, Ohio State University, Columbus, Ohio.

Sevier, R. A. (1994). Image is everything: Strategies for measuring, changing and maintaining your institution's image. White paper No. 1. Cedar Rapids, IA: Stamats Communications, Inc.

Soutar, G. N. \& Turner, J. (2002). Students' preferences for university: a conjoint analysis. The International Journal of Educational Management, 16, 40-45.

Van Niekerk, M. P. (2004). The national plan for higher education in South Africa and African indigenous knowledge systems: a case of conflicting value systems. South African Journal of Higher Education, $18(3), 115-126$.

\section{Appendix}

Table A1: Logistic Regression Analysis- Variables in the Equation

\begin{tabular}{|c|c|c|c|c|c|c|c|}
\hline & & B & S.E. & Wald & df & Sig. & Exp(B) \\
\hline \multirow[t]{10}{*}{ Step $1^{a}$} & Age & -.226 & .033 & 7.192 & 1 & .007 & 1.093 \\
\hline & gender(1) & .236 & 187 & 1.600 & 1 & .206 & 1.267 \\
\hline & Q9(1) & -.029 & 217 & .018 & 1 & .895 & .972 \\
\hline & Q7(1) & -.039 & 209 & .035 & 1 & .851 & .962 \\
\hline & section2.4 (CE) & & & 11.293 & 4 & .023 & \\
\hline & section $2.4(1)$ & -.103 & .335 & .094 & 1 & .759 & .902 \\
\hline & section $2.4(2)$ & .952 & .465 & 4.189 & 1 & .041 & 2.590 \\
\hline & section $2.4(3)$ & -.396 & .245 & 2.608 & 1 & 106 & .673 \\
\hline & section2.4(4) & -.485 & .251 & 3.715 & 1 & .054 & .616 \\
\hline & Constant & -1.882 & .740 & 6.468 & 1 & .011 & .152 \\
\hline
\end{tabular}

a. Variable(s) entered on step 1: age, gender, Q9, Q7, section2.4.

Table A2: Logistics Regression- Likelihood Ratio Tests

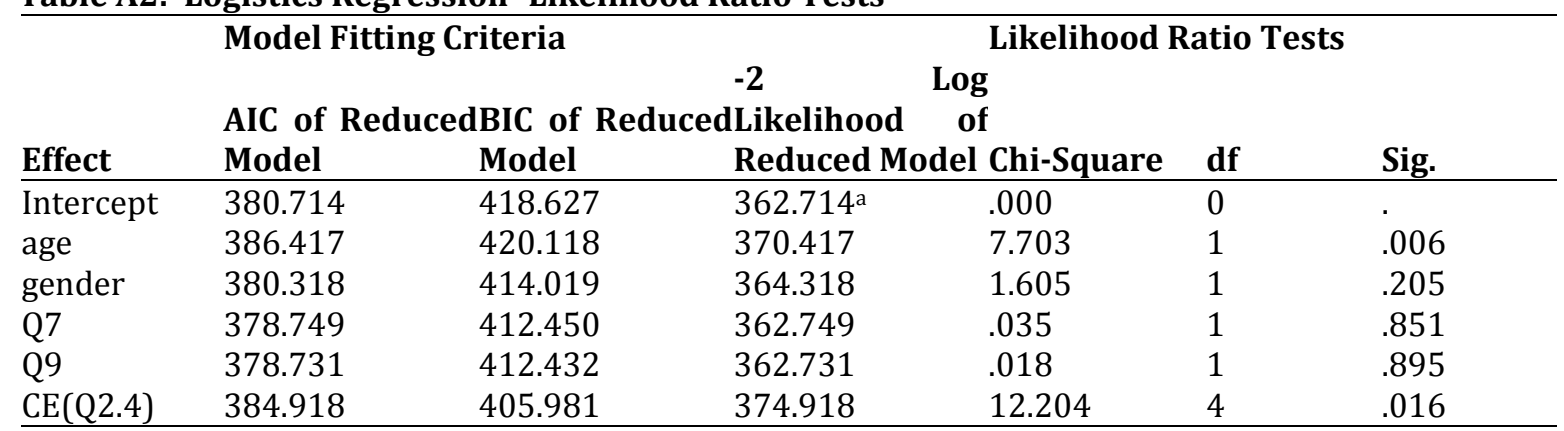

The chi-square statistic is the difference in -2 log-likelihoods between the final model and a reduced model. The reduced model is formed by omitting an effect from the final model. The null hypothesis is that all parameters of that effect are 0 .

a. This reduced model is equivalent to the final model because omitting the effect does not increase the degrees of freedom.

Table A3: Goodness-of-Fit

\begin{tabular}{llll}
\hline & Chi-Square & df & Sig. \\
\hline Pearson & 182.336 & 181 & .458 \\
Deviance & 231.735 & 181 & .006 \\
\hline
\end{tabular}


Table A4: Standardized Canonical Discriminant Function Coefficients

\begin{tabular}{lc}
\hline & Function \\
$\mathbf{1}$
\end{tabular}

